\title{
Equilibria and Kinetics of the Extraction of Nickel with 2-Pyridinecarbaldehyde 2-(5-substituted)pyridylhydrazones
}

\author{
Hajime IsHII, Tsugikatsu OdaShIMA and Takashi HaShImoto \\ Chemical Research Institute of Non-Aqueous Solutions, Tohoku University, Katahira, Sendai 980
}

\begin{abstract}
The equilibria and kinetics of the extraction of nickel ion with benzene solutions of 2-pyridinecarbaldehyde 2-(5substituted)pyridylhydrazones have been studied at $25 \pm 0.1^{\circ} \mathrm{C}$ and an ionic strength of 0.2 . The extracted species was found to be $\mathrm{NiL}_{2}$ for each hydrazone, where $\mathrm{L}$ denotes the undissociable part of the hydrazone. Partition constants of the hydrazones and extraction constants of their nickel complexes between an aqueous and a benzene phase were determined. The rate of extraction was found to be best described by a two-term expression, both terms being first order in nickel ion and $\mathrm{HL}$ concentrations. The first term has zero dependence on hydrogen ion concentration, whereas the second is inversely first order with respect to hydrogen ion concentration. These results support the hypothesis that the rate-determining steps involve two concurrent reactions of nickel ion with neutral and anionic forms of the hydrazones. Kinetic data and activation parameters for the first reaction were determined, but those for the second one involving the anion could not be obtained.
\end{abstract}

Keywords 2-Pyridinecarbaldehyde 2-(5-substituted)pyridylhydrazones, nickel, nickel-hydrazone complex; extraction equilibria, extraction kinetics

In a previous paper $^{1}$ we reported that (1) three hydrazones, in which the 5-position of the pyridine ring in the hydrazine moiety of 2-pyridinecarbaldehyde 2pyridylhydrazone (PAPH) was substituted by a methyl, chloro or nitro group (PAMPH, PACPH and PANPH, respectively), form metal complexes which are extractable into organic solvents and have large molar absorptivities and (2) especially PANPH, into which a strong electron-withdrawing group is introduced, forms complexes, with copper(II) and nickel(II), having molar absorptivities of the order of $10^{5}$. On these bases, a highly sensitive and selective extraction-spectrophotometric method for the determination of nickel with PANPH was proposed. In order to more fully understand the complexation reactions of these hydrazones with nickel(II) and the extraction behavior of the complexes, the equilibria, kinetics and mechanisms of extraction of nickel(II) with these hydrazones into benzene were studied in detail.

\section{Experimental}

\section{Reagents}

The hydrazones (PAMPH, PACPH, PANPH and PAPH) were synthesized as described in a previous paper.' All other reagents were of analytical-reagent grade. Distilled, de-ionized water was used throughout the experiments.

\section{Apparatus}

The following instruments were used: a Hitachi 139 spectrophotometer with 10-mm cells, a Toa HM-5B pH meter, and Iwaki KM shaker and a Haake FK-2 thermoelectric circulating bath. All extractions were performed by shaking samples in 100-ml separating funnels jacketed so that the systems could be kept at constant temperature $\left(25 \pm 0.1^{\circ} \mathrm{C}\right)$ by means of water circulated from the thermostatic bath.

\section{Procedures}

Partition of PANPH. A 20-ml aliquot of an aqueous solution containing $0.5-4.0 \mathrm{ml}$ of $1 \mathrm{M}$ sodium hydroxide solution and sodium perchlorate to maintain the ionic strength to 0.2 was placed in a separating funnel along with $20 \mathrm{ml}$ of a benzene solution of PANPH. The funnel was shaken for $2 \mathrm{~h}$ and allowed to stand for the phase separation. A $10-\mathrm{ml}$ portion of the aqueous phase was transferred into a $25-\mathrm{ml}$ calibrated flask, to which were added $5 \mathrm{ml}$ of $5 \mathrm{M}$ sodium hydroxide solution to change all of PANPH to its anionic form, $\mathrm{L}^{-}, 6 \mathrm{ml}$ of ethanol and enough water to dilute to the mark. The absorbance of the solution was measured at $495 \mathrm{~nm}$ against water, the concentration of PANPH being obtained from a calibration graph for $\mathrm{L}^{-}$ prepared under the identical conditions. The equilibrium concentration of PANPH in the organic phase was calculated by subtracting the aqueous equilibrium concentration from the initial concentration. 
Partition of other hydrazones. As the secondary amino group of PAMPH, PACPH and PAPH does not much or at all dissociate at $\mathrm{pH}$ values below 14 , the calibration graphs for the $\mathrm{L}^{-}$species of these hydrazones could not be prepared. Hence the partition of these hydrazones was studied in the $\mathrm{pH}$ region from 9 to 12 using ammonia buffers in a similar way to that stated above, in which the calibration graph for the neutral form, $\mathrm{HL}$, of each hydrazone was used for obtaining the equilibrium concentration in the aqueous phase.

Distribution of nickel. The distribution of nickel between the benzene and aqueous phases was determined as a function of the hydrogen ion concentration. A 10-ml aliquot of an aqueous solution containing 4.05 $\mu \mathrm{g}(2.02 \mu \mathrm{g}$ for the nickel-PANPH system) of nickel(II), acetate or borate buffer and sodium perchlorate to maintain the ionic strength to 0.2 was placed in a separating funnel along with $10 \mathrm{ml}$ of a benzene solution of the hydrazone. The funnel was shaken for $12 \mathrm{~h}$ to ensure that the equilibrium was achieved. After the phases separated, the equilibrium concentration of nickel in the organic phase was determined by measuring the absorbance of the extract at each absorption maximum wavelength against each reagent blank. The equilibrium concentration of nickel in the aqueous phase was calculated by subtracting the organic equilibrium concentration from the initial concentration.

Kinetic procedure. Preliminary spectrophotometric equilibrium experiments showed that the nickel(II) in the aqueous phase was completely extracted into benzene as a $1: 2$ chelate $\left(\mathrm{NiL}_{2}\right)$ under the conditions employed in the kinetic runs. The kinetic runs were carried out under pseudo-first-order conditions, the hydrazone in the benzene phase being in large excess over nickel(II) in the aqueous phase.

A 10-ml aliquot of an aqueous solution containing $2.02 \mu \mathrm{g}$ of nickel(II), acetate buffer and sodium perchlorate to maintain the ionic strength to 0.2 was placed in a $100-\mathrm{ml}$ separating funnel. After thermal equilibration ( $c a .30 \mathrm{~min}$ ), an equal volume of a benzene solution of the hydrazone was carefully added. The reaction was begun by shaking. The experiments were carried out in the "plateau" region, i.e., where a further increase of shaking speed had no effect on the rate of extraction. After shaking for a predetermined time (from 5 to $30 \mathrm{~min}$ ), the funnel was allowed to stand for $10 \mathrm{~min}$ to ensure complete phase separation. The absorbance of the organic phase was measured at each absorption maximum wavelength against each reagent blank. The nickel concentration was obtained from each calibration graph prepared under the identical conditions. The equilibrium concentration of nickel in the aqueous phase was calculated by subtracting the organic equilibrium concentration from the initial concentration.
Table 1 Partition constants $\left(K_{\mathrm{D}}\right)$ of hydrazones and extraction constants $\left(K_{\mathrm{ex}}\right)$ of their nickel(II) complexes at an ionic strength of 0.2 and at $25 \pm 0.1^{\circ} \mathrm{C}$

\begin{tabular}{lccc}
\hline Hydrazone & $\log K_{\mathrm{D}}$ & $\log K_{\text {ex }}$ & $\begin{array}{c}\text { Slope of } \log D_{\mathrm{Ni}} \\
v s . \text { pH plots }\end{array}$ \\
\hline PAMPH & 2.27 & -8.00 & 1.98 \\
PAPH & 1.58 & -8.76 & 2.02 \\
PACPH & 2.95 & -5.16 & 1.98 \\
PANPH & 1.92 & 0.24 & 1.98 \\
\hline
\end{tabular}

\section{Results and Discussion}

\section{Equilibrium of nickel extraction}

Partition of hydrazones. As is evident from the structure, each hydrazone exists in solution in one of the following forms, depending on $\mathrm{pH}$ :

$$
\mathrm{H}_{3} \mathrm{~L}^{2+} \stackrel{k_{\mathrm{al}}}{=} \mathrm{H}_{2} \mathrm{~L}^{+} \stackrel{k_{\mathrm{a} 2}}{=} \mathrm{HL} \stackrel{k_{\mathrm{a} 3}}{=} \mathrm{L}^{-}
$$

where $k_{\mathrm{a} 1}, k_{\mathrm{a} 2}$ and $k_{\mathrm{a} 3}$ are the acid dissociation constants.

The distribution ratio, $D_{\mathrm{L}}$, of each hydrazone between an aqueous and a benzene phase can be expressed as Eq.(1) and is rewritten as Eq.(2) by using the acid dissociation constants and the partition constant, $K_{\mathrm{D}}$ :

$$
\begin{aligned}
& D_{\mathrm{L}}=\frac{[\mathrm{HL}]_{\text {org }}}{\left[\mathrm{H}_{3} \mathrm{~L}^{2+}\right]+\left[\mathrm{H}_{2} \mathrm{~L}^{+}\right]+[\mathrm{HL}]+\left[\mathrm{L}^{-}\right]} \\
& D_{\mathrm{L}}=\frac{K_{\mathrm{D}}}{\frac{\left[\mathrm{H}^{+}\right]^{2}}{k_{\mathrm{a} 1} k_{\mathrm{a} 2}}+\frac{\left[\mathrm{H}^{+}\right]}{k_{\mathrm{a} 2}}+1+\frac{k_{\mathrm{a} 3}}{\left[\mathrm{H}^{+}\right]}}
\end{aligned}
$$

where the subscript org denotes the concentration in the organic phase. As the values of $k_{\mathrm{a} 1}, k_{\mathrm{a} 2}$ and $k_{\mathrm{a}_{3}}$ are already known ${ }^{1}$, the value of $K_{\mathrm{D}}$ can be calculated from Eq. (2) when a series of values of $D_{\mathrm{L}}$ as a function of $\mathrm{pH}$ is obtained experimentally. The values of $K_{\mathrm{D}}$ for the hydrazones obtained in this manner are shown in Table 1 , from this it may be seen that the partition constant of PAPH is not so large as expected, but is increased by about $0.7,1.4$ and 0.3 units in logarithmic expression by introducing a methly, chloro or nitro group, respectively.

Distribution of nickel. The overall reaction in the extraction of nickel with each hydrazone (HL) may be expressed as

$$
\mathrm{Ni}^{2+}+n \mathrm{HL}_{\text {org }} \leftrightharpoons \mathrm{NiL}_{n, \text { org }}+n \mathrm{H}^{+} \text {. }
$$

The extraction constant, $K_{\text {ex }}$, is defined as Eq.(4) and is rewritten as Eq.(5) by using the distribution ratio of nickel, $D_{\text {Ni. }}$

$$
\begin{aligned}
& K_{\mathrm{ex}}=\frac{[\mathrm{NiL}]_{\text {org }}\left[\mathrm{H}^{+}\right]^{n}}{\left[\mathrm{Ni}^{2}\right][\mathrm{HL}]_{\text {org }}^{n}} \ldots \ldots \ldots \ldots \ldots \ldots \ldots \ldots \ldots \\
& \log D_{\mathrm{Ni}}=\log K_{\mathrm{ex}}+n \log [\mathrm{HL}]_{\text {org }}+n \mathrm{pH} \ldots \ldots \ldots \ldots
\end{aligned}
$$




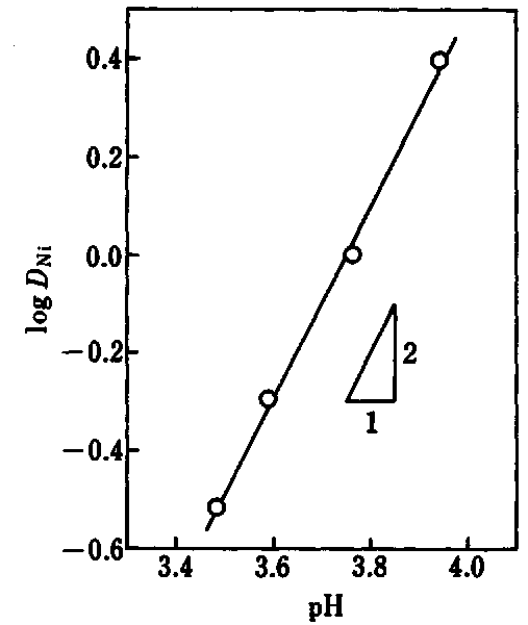

Fig. 1 Plot of $\log D_{\mathrm{Ni}} v s$. pH for the extraction of nickel(II) with PANPH at an ionic strength of 0.2 and at $25 \pm 0.1^{\circ} \mathrm{C}$. $\mathrm{Ni}^{2+}, 2.02 \mu \mathrm{g} / 10 \mathrm{ml}$; PANPH, $1.5 \times 10^{-4} \mathrm{M}$; shaking time, $12 \mathrm{~h}$.

Equation (5) implies that the plots of $\log D_{\mathrm{Ni}}$ against the $\mathrm{pH}$ at a constant hydrazone concentration give a straight line with a slope of $\boldsymbol{n}$ for nickel, the value of $K_{\mathrm{ex}}$ being calculated from the intercept of this line. As an example, the plot of $\log D_{\mathrm{Ni}}$ versus $\mathrm{pH}$ in the nickel(II)PANPH system is shown in Fig. 1; results for each extraction system are summarized in Table 1 . Thus it can be concluded that only a $1: 2$ complex, $\mathrm{NiL}_{2}$, is extracted into benzene in each extraction system, which is in accord with the result obtained by the continuous variation method in the nickel(II)-PANPH system. ${ }^{1}$

\section{Kinetics of nickel extraction}

Generally, since the rate of complexation depends on the concentrations of metal ion, ligand and hydrogen ion, the rate of formation of the nickel complex of each hydrazone can be assumed to be

$$
-\frac{\mathrm{d}\left[\mathrm{Ni}^{2+}\right]}{\mathrm{d} t}=k^{\prime}\left[\mathrm{Ni}^{2+}\right]^{a}[\mathrm{HL}]_{\text {org }}^{b}\left[\mathrm{H}^{+}\right]^{c}
$$

where $t$ is the reaction time, $k^{\prime}$ is the rate constant and $a, b$ and $c$ are the reaction orders with respect to the concentrations of nickel ion, hydrazone and hydrogen ion, respectively.

Reaction order with respect to nickel ion concentration.

Under a pseudo-first-order excess of the hydrazone ligand and at a constant $\mathrm{pH}$, the rate of the extraction of nickel(II) ion with the hydrazone into benzene is expressed as

$$
-\frac{\mathrm{d}\left[\mathrm{Ni}^{2+}\right]}{\mathrm{d} t}=k_{\mathrm{obs} 0}\left[\mathrm{Ni}^{2+}\right]^{a}
$$

where $k_{\text {obsd }}$ is the observed pseudo-first-order rate constant. If $a=1$, we can integrate Eq.(7) and derive Eq.(8):

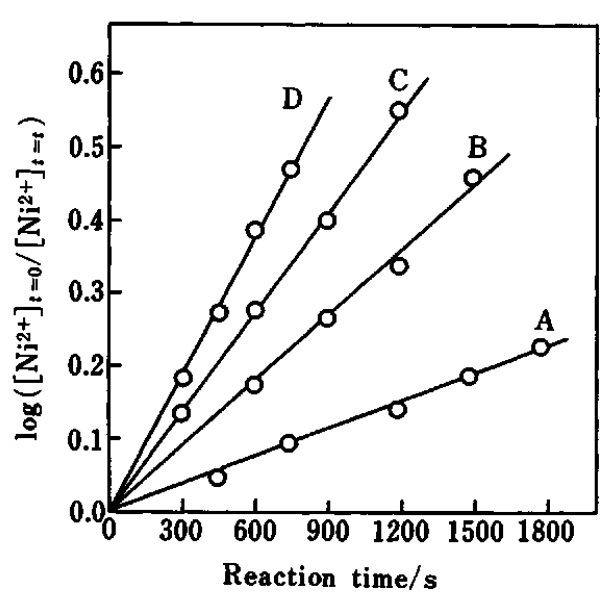

Fig. 2 Plots of $\log \left(\left[\mathrm{Ni}^{2+}\right]_{t=0} /\left[\mathrm{Ni}^{2+}\right]_{t=t}\right)$ vs. reaction time for the nickel-PANPH system. $\mathrm{Ni}^{2+}, 1.7 \times 10^{-4} \mathrm{M}$; PANPH: A, $5.0 \times 10^{-5} ; \mathrm{B}, 1.0 \times 10^{-4} ; \mathrm{C}, 1.5 \times 10^{-4} ;$ and $\mathrm{D}, 2.0 \times 10^{-4} \mathrm{M} ; \mathrm{pH}$, 6.0 ; ionic strength, 0.2 ; temperature, $25 \pm 0.1^{\circ} \mathrm{C}$; wavelength, $507 \mathrm{~nm}$.

$$
\log \frac{\left[\mathrm{Ni}^{2+}\right]_{l=0}}{\left[\mathrm{Ni}^{2+}\right]_{l=l}}=k_{\text {obsd }} t \ldots \ldots \ldots \ldots \ldots \ldots \ldots \ldots \ldots
$$

where $\left[\mathrm{Ni}^{2+}\right]_{t=0}$ and $\left[\mathrm{Ni}^{2+}\right]_{t=t}$ are the concentration of nickel ion in the aqueous phase at $t=0$ and $t$, respectively. Equation (8) means that by experimentally ascertaining the linearity of a graph of $\log \left(\left[\mathrm{Ni}^{2+}\right]_{l=0} /\right.$ $\left[\mathrm{Ni}^{2+}\right]_{t=1}$ ) versus $t$, we can know whether $a=1$ or not and can obtain the $k_{\text {obsd }}$ value from the slope of the graph. In fact, the plots of $\log \left(\left[\mathrm{Ni}^{2+}\right]_{l=0} /\left[\mathrm{Ni}^{2+}\right]_{l=t}\right)$ versus $t$ for the nickel-PAPH, -PAMPH, -PACPH and -PANPH systems were all linear and through the origin, which indicate that the complexation reactions of nickel(II) with the hydrazones in these extractions are all first order with respect to the nickel(II) concentration, i.e., $a=1$. As an example, the plots for the nickel-PANPH system are shown in Fig. 2.

Reaction order with respect to concentrations of hydrogen ion and hydrazone. The plots of $k_{\mathrm{obsd}}$ versus $1 /\left[\mathrm{H}^{+}\right]$at various [HL] org for the nickel-PANPH system gave linear relations having intercepts, as shown in Fig. 3. The values of both intercepts and slopes of these lines were proportional to [HL] org, as shown in Fig. 4. Similar results to those in Figs. 3 and 4 were also obtained for the other hydrazone-nickel systems. These results demonstrate that the reaction order of these extractions with respect to the hydrogen ion concentration is 0 and -1 , i.e., $c=0$ and -1 , the order in the hydrazone concentration being 1 , i.e., $b=1$. These results are similar to those of nickel extraction with 8-quinolinol ${ }^{2}$, 7-dodecyl-8-quinolinol ${ }^{3}$ and 8-mercaptoquinoline ${ }^{4}$, which suggest that two concurrent $1: 1$ nickel complex formation steps control the rate of extraction.

Rate-determining steps, rate constants and activation parameters for the complex formation. Since the major 


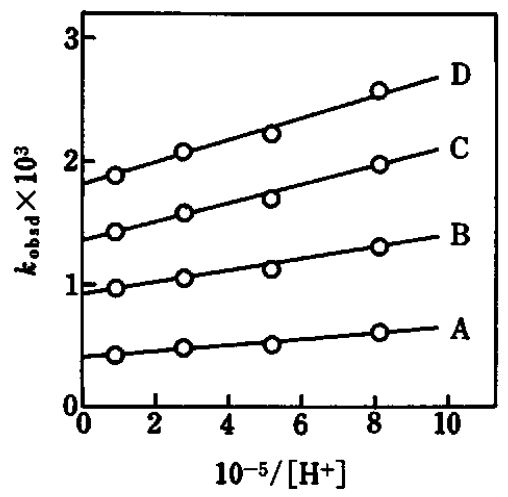

Fig. 3 Plots of $\log k_{\text {obsd }} v s$. $1 /\left[\mathrm{H}^{+}\right]$for the nickel-PANPH

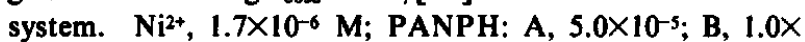
$10^{-4}$; C, I.5 $\times 10^{-4}$; and $\mathrm{D}, 2.0 \times 10^{-4} \mathrm{M}$; ionic strength, 0.2 ; temperature, $25 \pm 0.1^{\circ} \mathrm{C}$.

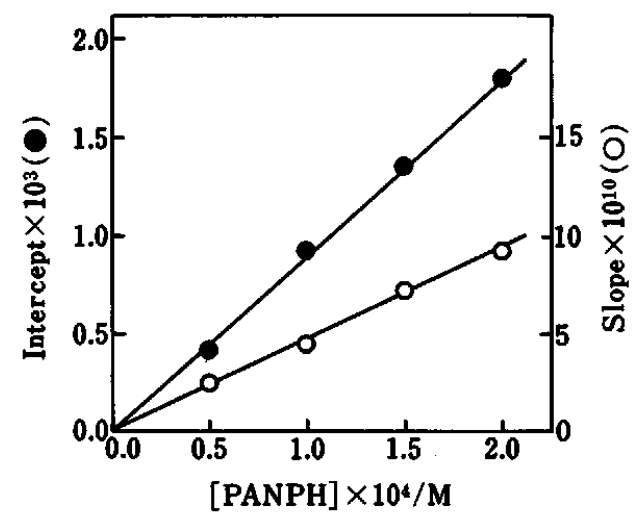

Fig. 4 Slope and intercept of Fig. 3 as a function of the concentration of PANPH in benzene.

forms of each hydrazone in aqueous phase in the range of $\mathrm{pH}$ studied are $\mathrm{HL}$ and $\mathrm{L}^{-}$, as is evident from their $k_{\mathrm{a}}$ values $^{1}$, the equilibria and the reactions involved in the formation of mononickel complex are shown in Eqs. (9)-(12). $k_{\mathrm{HL}}$ and $k_{\mathrm{L}}$ represent the rate constants of respective reaction steps.

$$
\begin{aligned}
& \mathrm{HL}_{\text {org }} \leftrightharpoons \mathrm{HL} \quad K_{\mathrm{D}}=[\mathrm{HL}]_{\text {org }} /[\mathrm{HL}] \ldots \ldots \ldots \text { (9) } \\
& \mathrm{HL} \leftrightharpoons \mathrm{H}^{+}+\mathrm{L}^{-} \quad k_{\mathrm{a} 3}=\left[\mathrm{H}^{+}\right][\mathrm{L}-] /[\mathrm{HL}] \ldots(10) \\
& \mathrm{Ni}^{2+}+\mathrm{HL} \stackrel{k_{H L}}{\longrightarrow} \mathrm{NiL}^{+}+\mathrm{H}^{+} \ldots \ldots \ldots \ldots \ldots \ldots \ldots(11) \\
& \mathrm{Ni}^{2+}+\mathrm{L}^{-} \stackrel{k_{\mathrm{L}}}{\longrightarrow} \mathrm{NiL}^{+}
\end{aligned}
$$

On the basis of the above results, the rate-determining steps are considered to be competitive reactions of
Table 2 Kinetic data and activation parameters for the complexation reaction of nickel(II) with hydrazones at an ionic strength of 0.2 and at $25 \pm 0.1^{\circ} \mathrm{C}$

\begin{tabular}{lccccc}
\hline $\begin{array}{l}\text { Hydra- } \\
\text { zone }\end{array}$ & $\begin{array}{c}K_{\mathrm{HL}} / \\
1 \mathrm{~mol}^{-1} \mathrm{~s}^{-1}\end{array}$ & $\begin{array}{c}E_{\mathrm{a}} / \\
\mathrm{kJ} \mathrm{mol}^{-1}\end{array}$ & $\begin{array}{c}\Delta H^{\ddagger} / \\
\mathrm{kJ} \mathrm{mol}^{-1}\end{array}$ & $\begin{array}{c}\Delta S^{\ddagger} / \\
\mathrm{J} \mathrm{K}^{-1} \mathrm{~mol}^{-1}\end{array}$ & $\begin{array}{c}\Delta G^{\ddagger} \\
\mathrm{kJ} \mathrm{mol}^{-1}\end{array}$ \\
\hline PAMPH & $1.10 \times 10^{3}$ & 44.4 & 41.8 & -46.0 & 55.6 \\
PAPH & $2.70 \times 10^{2}$ & 40.2 & 37.7 & -72.0 & 59.0 \\
PACPH & $9.90 \times 10^{3}$ & 52.7 & 50.2 & 0.0 & 50.2 \\
PANPH & $1.76 \times 10^{3}$ & 67.8 & 65.3 & 36.4 & 54.4 \\
\hline
\end{tabular}

nickel ion with undissociated and dissociated forms of the hydrazone in aqueous phase [Eqs. (11) and (12)], so the rate equation for the complexation reaction of nickel ion with the hydrazone can be expressed as

$$
\begin{aligned}
-\frac{\mathrm{d}\left[\mathrm{Ni}^{+}\right]}{\mathrm{d} t} & =k_{\mathrm{HL}}\left[\mathrm{Ni}^{2+}\right][\mathrm{HL}]+k_{\mathrm{L}}\left[\mathrm{Ni}^{2+}\right]\left[\mathrm{L}^{-}\right] \\
& =\left(k_{\mathrm{HL}}+k_{\mathrm{L}} \frac{k_{\mathrm{a}} 3}{\left[\mathrm{H}^{+}\right]}\right) \frac{\left[\mathrm{Ni}^{2+}\right][\mathrm{HL}]_{\text {org }}}{K_{\mathrm{D}}} .
\end{aligned}
$$

The value of $k_{\mathrm{HL}}$ for the PANPH-nickel system is obtained from the slope of the linear plots in Fig. 4; this is shown in Table 2 along with the values for the other hydrazone-nickel systems obtained in a similar way.

These values of $k_{\mathrm{HL}}$ appear to be reasonable, because they are close to the rate constants for nickel ion with neutral ligands in aqueous solution. ${ }^{3,5,6}$ This fact clearly indicates that the $1: 1$ complex formation reaction of the undissociated form of each hydrazone, represented by Eq.(11), occurs in the aqueous phase. The activation parameters $\left(E_{\mathrm{a}}, \Delta H^{\ddagger}, \Delta S^{\ddagger}\right.$ and $\left.\Delta G^{\ddagger}\right)$ for each system calculated from Arrhenius plots are also summarized in Table 2.

The value of $k_{\mathrm{L}}$ for each system, on the other hand, could not be obtained because no reliable enough value of the acid dissociation constant $\left(k_{\mathrm{a} 3}\right)$ to use in the calculation of the $k_{\mathrm{L}}$ value could be obtained.

\section{References}

1. H. Ishii, T, Odashima and T. Hashimoto, Anal. Sci., 3 347 (1987).

2. K. Yamada, K. Nakagawa, K. Haraguchi and S. Ito, Nippon Kagaku Kaishi, 1975, 294.

3. K. Haraguchi and H. Freiser, Inorg. Chem., 22, 1187 (1983).

4. K. Haraguchi and H. Freiser, Anal. Chem., 55, 656 (1983).

5. D. B. Rorabacher, Inorg. Chem., 5, 1891 (1966).

6. S. Funahashi and M. Tanaka, Inorg. Chem., 8, 2159 (1969). 